\title{
Spirometry-adjusted fraction of exhaled nitric oxide increases accuracy for assessment of asthma control in children
}

\author{
Carla Martins $^{1}$ (D) | Diana Silva ${ }^{1,2}$ | Milton Severo ${ }^{2,3}$ | João Rufo ${ }^{2,4}$ (D) | \\ Inês Paciência $^{2,4}$ | Joana Madureira ${ }^{4}$ | Patrícia Padrão ${ }^{5}$ | Pedro Moreira ${ }^{5}$ | \\ Luís Delgado $^{1,2}$ | Eduardo Oliveira Fernandes ${ }^{4}$ | Henrique Barros ${ }^{2,3}$ | \\ Pekka Malmberg $^{6}$ | André Moreira ${ }^{1,2,3,5}$
}

\author{
${ }^{1}$ Department of Immunoallergology, Centro \\ Hospitalar de São João, Porto, Portugal \\ ${ }^{2}$ Faculty of Medicine, Basic and Clinical \\ Immunology, University of Porto, Porto, \\ Portugal \\ ${ }^{3}$ Institute of Public Health, University of Porto, \\ Porto, Portugal \\ ${ }^{4}$ Institute of Science and Innovation in \\ Mechanical and Industrial Engineering, Porto, \\ Portugal \\ ${ }^{5}$ Faculty of Nutrition and Food \\ Sciences, University of Porto, Porto, Portugal \\ ${ }^{6}$ Department of Allergology, University of \\ Helsinki and Helsinki University Hospital, \\ Helsinki, Finland

\section{Correspondence} \\ Carla Martins, Serviço de Imunoalergologia, \\ Centro Hospitalar de São João, Porto, \\ Portugal. \\ Email: cdanielaam@gmail.com

\section{Funding information} \\ Health, Comfort and Energy in the Built \\ Environment (HEBE), Grant/Award Number: \\ NORTE-01-0145-FEDER-000010; Programa \\ Operacional Regional do Norte, Grant/Award \\ Number: NORTE2020; Fundo Europeu \\ de Desenvolvimento Regional (FEDER); \\ Foundation for Science and Technology \\ schoolarships, Grant/Award Number: \\ SFRH/BD/108605/2015 and SFRH/ \\ $\mathrm{BD} / 112269 / 2015$
}

\begin{abstract}
Spirometry and exhaled nitric oxide are two important complimentary tools to identify and assess asthma control in children. We aimed to determine the ability of a new suggested spirometry-adjusted fraction of exhaled nitric oxide (NO) index in doing that. A random sample of 1602 schoolchildren were screened by a health questionnaire, skin prick tests, spirometry with bronchodilation and exhaled NO. A total of 662 children were included with median (IQR) exhaled NO 11(14) ppb. Receiver operating characteristic (ROC) curves using exhaled NO equations from Malmberg, Kovesi and Buchvald, and spirometry-adjusted fraction of exhaled NO values were applied to identify asthmatic children and uncontrolled asthma. Receiver operating characteristic (ROC) curves failed to identify asthmatic children (all AUC < 0.700). Spirometryadjusted fraction of exhaled $\mathrm{NO} / \mathrm{FEV}_{1}$ (AUC $=0.712 ; P=.010$ ) and $\mathrm{NO} / \mathrm{FEF}_{25 \%-75 \%}$ ( $A \cup C=0.735 P=.004$ ) had a fair and increased ability to identify uncontrolled disease compared with exhaled NO (AUC $=0.707 ; P=.011$ ) or the Malmberg equation (AUC $=0.701 ; P=.014)$. Sensitivity and specificity identifying non-controlled asthma were $59 \%$ and $81 \%$, respectively, for the cut-off value of $9.7 \mathrm{ppb} / \mathrm{L}$ for exhaled $\mathrm{NO} / \mathrm{FEV}_{1}$, and $40 \%$ and $100 \%$ for $15.7 \mathrm{ppb} / \mathrm{L} / \mathrm{s}$ for exhaled $\mathrm{NO} / \mathrm{FEF}_{25 \%-75 \%}$. Exhaled NO did not allow to identify childhood asthma. Spirometry-adjusted fraction of exhaled NO performed better-assessing asthma control in children. Thus, although more validation studies are needed, we suggest its use in epidemiological studies to assess asthma control.
\end{abstract}

\section{KEYWORDS}

asthma, asthma control, children, exhaled nitric oxide, spirometry

\section{1 | BACKGROUND}

Exhaled nitric oxide (NO) has been used as non-invasive, easy to measure, reproducible and immediately available biomarker of airway inflammation in allergic diseases. ${ }^{1}$ Standardized procedures for its measurement ${ }^{2}$ and clinical use ${ }^{3}$ have already been published, with a strong level of evidence in the diagnosis of eosinophilic airway inflammation and for monitoring airway inflammation in patients with asthma. $^{3}$ In fact, the expression of inducible nitric oxide synthetase mRNA has been shown to be increased in the airways of subjects with asthma ${ }^{4}$ and to be downregulated by the use of inhaled steroids. ${ }^{5}$ 
Although the diagnostic accuracy of exhaled NO in the identification of asthma in children is moderate, it suggests that it might be a promising too ${ }^{6}$ and the confounding or effect modification of atopy is believed to be a key feature that limits the usefulness of exhaled NO in asthma diagnosis.

Exhaled nitric oxide has shown to be efficient in guiding medication management, as a reduction of $20 \%$ in exhaled NO is considered indicative of a response to anti-inflammatory therapy. ${ }^{3}$ However, no significant advantage was seen with the specific use of exhaled NO-driven protocols to guide asthma treatment compared with other methods, ${ }^{7,8}$ and according to GINA guidelines, ${ }^{9}$ treatment of asthmatic children usually relies on symptoms reported by the child and/or guardians. Furthermore, correlations between airway inflammation and symptoms, asthma control and asthma severity are weak or absent. ${ }^{1,9-11}$ In steroid-naïve patients, high exhaled NO levels predict a good response to inhaled corticosteroids (ICS) treatment, and a low level of exhaled NO in adults in ICS treatment is associated with reduced likelihood ratio of exacerbation. ${ }^{12}$ Until now, it is not possible to provide clear recommendations for the utility of the exhaled NO in asthma management, as studies failed to show an overall benefit in the rate of exacerbations as well as in asthma control, lung function and use of oral corticosteroids during exacerbations. ${ }^{13}$ In a recent study, exhaled NO was used in relation to $\mathrm{FEV}_{1}$ (exhaled NO/FEV ${ }_{1}$ ) to distinguish patients with asthma from those without with promising results. ${ }^{14}$ This kind of approach could be a way to minimize the influence of baseline bronchial constriction on exhaled NO.

With this study, we aimed to assess the ability of spirometryadjusted fraction of exhaled nitric oxide to identify and assess asthma control in children, in comparison with traditional approaches.

\section{2 | METHODS}

\section{1 | Study design}

This study is a cross-sectional analysis of data of 1602 children, aged between 8 and 12 years. Assessments were carried out between January and May of 2014 and 2015 (Data S1). The questionnaire included previous and current respiratory symptoms, questions about congenital anomalies, systemic diseases, long-term medication and environmental exposure.

\subsection{Assessments}

All the participants completed anthropometric measurements. Skin prick tests were performed on the forearm using a QuickTestTM applicator containing house dust mite, mix of weeds, mix of grasses, cat dander, dog dander and Alternaria alternata, negative and a positive controls (Hall Allergy, Netherlands). Exhaled NO was analysed using a NOBreath ${ }^{\circledR}$ (Bedfont ${ }^{\circledR}$ Scientific Ltd, Maidstone, UK). Spirometry was carried out using Spirolab spirometer (MIR, Italy) and the WINSPIROPRO ${ }^{\circledR}$ software. Reversibility testing was performed using four separate doses of $100 \mu$ g salbutamol through a space chamber-coupled MDI. A detailed description of assessment methods is presented in the online repository.

\section{3 | Definitions and participants}

Current asthma was defined as symptomatic children (wheezing in the last 12 months, or wheezing with exercise, or waking at night with wheezing in the last months, or coughing at night in the last 12 months or coughing more than 3 months in the last year) with reported medical diagnosis or evidence of airway reversibility. ${ }^{15}$ Uncontrolled asthma was defined as an increase of at least $12 \%$ of the forced expiratory volume in 1-second (FEV1) after bronchodilation test or respiratory symptoms in the previous weeks with exhaled NO levels higher than 35 ppb. ${ }^{16}$ The control group was composed by all included participants who do not meet the asthma group inclusion criteria.

\section{4 | Statistical analysis}

Data were presented as a mean (SD), median and interquartile range (IQR) or proportions accordingly to the type of data. Two-sample $t$ test or Mann-Whitney was used to compare data between groups when appropriate, and chi-square test to compare proportions. Receiver operating characteristic (ROC) analysis was performed, in order to evaluate the ability of exhaled NO to detect children with asthma and to detect uncontrolled asthma. Agreement between ATS classification and a measure of control defined by our composite scores with exhaled NO adjusted for $\mathrm{FEV}_{1}$ or $\mathrm{FEF}_{25 \%-75 \%}$ was assessed by Cohen's kappa coefficient. IBM SPSS Statistics for Windows (Version 21.0. Armonk, NY, USA: IBM Corp.) was used for data analysis and for drawing graphs. All statistical data with $P<.05$ were considered significant.

\section{5 | Ethics statement}

Data collection was approved by the University Ethics Committee, and a written informed consent was obtained from each participant caregiver.

\section{3 | RESULTS}

Exclusion criteria were inability to correctly perform spirometry or exhaled NO manoeuvres, incomplete responses to the questionnaire, refuse to perform skin prick tests by children or guardians.

A total of 662 children were enrolled (Data S1), 74 (11.2\%) were included in the asthma group, and a positive bronchodilation test was found in 52 (8.0\%). Atopic children represented about a third (35.3\%) of the included participants and presented significantly higher exhaled NO levels when compared to non-atopic (Table 1).

The accuracy of absolute values of exhaled NO (AUC $=0.620$, $P=.001$ ), as well as of the Malmberg (AUC $=0.620, P=.001$ ) and Kovesi (AUC $=0.621, P=.001$ ) predicted values, was poor to identify asthmatic children (Fig. S2). Using the low, normal or high score values, 


\begin{tabular}{|c|c|c|c|c|}
\hline & $\begin{array}{l}\text { Total } \\
\mathrm{n}=662\end{array}$ & $\begin{array}{l}\text { Atopic } \\
n=234\end{array}$ & $\begin{array}{l}\text { Asthmatic } \\
\mathrm{n}=74\end{array}$ & $P$ value \\
\hline Ageyears, mean (SD) & $8.7(0.8)$ & $8.7(0.8)$ & $8.7(0.8)$ & $>.05$ \\
\hline Male sex, n (\%) & $318(48.0 \%)$ & $107(45.7 \%)$ & $27(36.5 \%)$ & $<.05$ \\
\hline $\begin{array}{l}\mathrm{BMI} \mathrm{kg} / \mathrm{m}^{2}, \text { median } \\
\text { (IQR) }\end{array}$ & $17.0(3.9)$ & $17.5(4.0)$ & $17.5(4.3)$ & $>.05$ \\
\hline $\begin{array}{c}\text { Exhaled NO, ppb, } \\
\text { median (IQR) }\end{array}$ & $11(14)$ & $14(20)$ & $17(30)$ & $<.05$ \\
\hline $\mathrm{FVCL}$, mean (SD) & $1.91(0.33)$ & $1.90(0.33)$ & $1.83(0.33)$ & $<.05$ \\
\hline $\mathrm{FEV}_{1} \mathrm{~L}$, mean $(\mathrm{SD})$ & $1.76(0.28)$ & $1.75(0.28)$ & $1.65(0.30)$ & $<.05$ \\
\hline $\begin{array}{l}\mathrm{FEF}_{25 \%-75 \%} \mathrm{~L} / \mathrm{s} \text {, mean } \\
\text { (SD) }\end{array}$ & $2.33(0.55)$ & $2.28(0.56)$ & $2.09(0.62)$ & $<.05$ \\
\hline $\mathrm{FEV}_{1} / \mathrm{FVC}$, mean (SD) & $92.4(5.3)$ & $92.1(5.4)$ & $90.5(6.2)$ & $<.05$ \\
\hline Cough $\geq 3 /$ mo last year & $3.8 \%(23)$ & $3.6 \%(8)$ & $14.3 \%(10)$ & $<.05$ \\
\hline Cough in previous $3 \mathrm{mo}$ & $35.6 \%(236)$ & $40.2 \%(94)$ & $48.6 \%(36)$ & $<.05$ \\
\hline $\begin{array}{l}\text { Wheezing } \geq 4 \text { times last } \\
\text { year }\end{array}$ & $8.9 \%(15)$ & $9.8 \%(6)$ & $25.0 \%(10)$ & $<.05$ \\
\hline $\begin{array}{l}\text { Awakenings }>1 / \text { mo } \\
\text { with wheeze }\end{array}$ & $19.7 \%(31)$ & $23.2 \%(13)$ & $50.0 \%(20)$ & $<.05$ \\
\hline Positive Bronchodilation & $7.9 \%(52)$ & $9.4 \%(22)$ & $60.8 \%(45)$ & $<.05$ \\
\hline $\begin{array}{l}\text { Exhaled NO/FVC ppb/L } \\
\text { median (IQR) }\end{array}$ & $5.76(6.54)$ & $7.38(12.70)$ & $8.97(15.38)$ & $<.05$ \\
\hline $\begin{array}{l}\text { Exhaled NO/FEV } 1 \text { ppb/L } \\
\text { median (IQR) }\end{array}$ & $6.30(7.31)$ & $8.14(13.82)$ & $9.72(17.06)$ & $<.05$ \\
\hline $\begin{array}{l}\text { Exhaled NO/FEF } 25 \% \text { - } \\
75 \% \mathrm{ppb} / \mathrm{L} / \mathrm{s} \text { median } \\
\text { (IQR) }\end{array}$ & $4.63(5.88)$ & $5.93(11.01)$ & $8.36(16.41)$ & $<.05$ \\
\hline $\begin{array}{l}\text { Exhaled NO/ } \\
\mathrm{FEF}_{75 \%} \mathrm{ppb} / \mathrm{L} / \mathrm{s} \text { median } \\
(\mathrm{IQR})\end{array}$ & $8.39(11.23)$ & $10.92(20.00)$ & $17.23(29.01)$ & $<.05$ \\
\hline $\begin{array}{l}\text { Exhaled NO/PEF ppb/ } \\
\text { L/s median (IQR) }\end{array}$ & $2.97(3.58)$ & $3.69(5.89)$ & $4.89(8.33)$ & $<.05$ \\
\hline
\end{tabular}

TABLE 1 Study participants

QR, interquartile range; SD, standard deviation; the values identified in bold are statistically significant.

according to Buchvald classification, exhaled NO failed to do it with an even lower AUC (AUC = 0.595, $P=.008$ ). In non-atopic children, the diagnostic power of exhaled $\mathrm{NO}$ and all predictive equations failed to identify asthma, with AUC's ranging between 0.500 and 0.600 , while in atopics, a small but significant improvement was seen (AUC ranged from 0.600 to 0.650 ).

Precision to distinguish between asthmatic and non-asthmatic children was improved when exhaled NO adjusted for spirometry was used, as shown in Figure 1. The best ratios to identify asthma were exhaled $\mathrm{NO} / \mathrm{FEF}_{25 \%-75 \%}$ (AUC $=0.652, P<.001$ ) and exhaled NO/ $\mathrm{FEF}_{75 \%}$ (AUC $=0.646, P<.001$ ). Moreover, when analysing atopic and non-atopic participants, results did not differ.

To identify uncontrolled asthma, only absolute values of exhaled NO ( $A \cup C=0.707, P=.011$ ) and the Malmberg equation ( $A \cup C=0.701, P=.014$ ) allowed to distinguish between controlled and non-controlled patients, as shown in Figure 2. Using the spirometry-adjusted fraction of exhaled NO allowed us to identify uncontrolled asthma with a fair AUC for all ratios: exhaled NO/FEV
(AUC $=0.712, P=.010)$, exhaled $\mathrm{NO} / \mathrm{FEF}_{25 \%-75 \%} \quad(\mathrm{AUC}=0.735$, $P=.004)$, exhaled NO/FEF $75 \%$ (AUC $=0.733, P=.004)$ and exhaled NO/PEF (AUC $=0.709, P=.011$ ) (Figure 3). When considering only the non-atopic children with asthma $(n=41)$, ROC curves performed even better, obtaining AUC of $0.744(P=.028)$ for $\mathrm{FEV}_{1}$, AUC $=0.765(P=.010)$ for $\mathrm{FEF}_{25 \%-75 \%,}, \mathrm{AUC}=0.762(P=.011)$ for $\mathrm{FEF}_{75}$ and $\mathrm{AUC}=0.720(P=.033)$ for PEF. In the atopic group $(n=32)$, none of the exhaled NO adjusted for spirometry parameter could identify uncontrolled asthma.

The best cut-off values to identify uncontrolled asthma, and their respective specificity and sensibility are presented in Table 2. Exhaled NO adjusted for $\mathrm{FEV}_{1}$ presented the highest sensitivity in identifying uncontrolled asthma, while exhaled $\mathrm{NO} / \mathrm{FEF}_{25 \%-75 \%}$ and exhaled $\mathrm{NO} / \mathrm{FEF}_{75 \%}$ have the better specificity. When comparing with ATS cut-off levels for uncontrolled asthma (>35 ppb), a moderate-to-strong and a weakto-moderate agreements with exhaled NO/FEF $25 \%-75 \%$ ( $>15.7 \mathrm{ppb} / \mathrm{L} / \mathrm{s}$ ) and exhaled NO/FEV $(>9.72 \mathrm{ppb} / \mathrm{L}$ ) were seen, respectively, $K=0.771$ (95\%Cl, 0.689-0.853) and $K=0.541$ (95\% Cl, 0.454-0.628) (Fig.S3). 

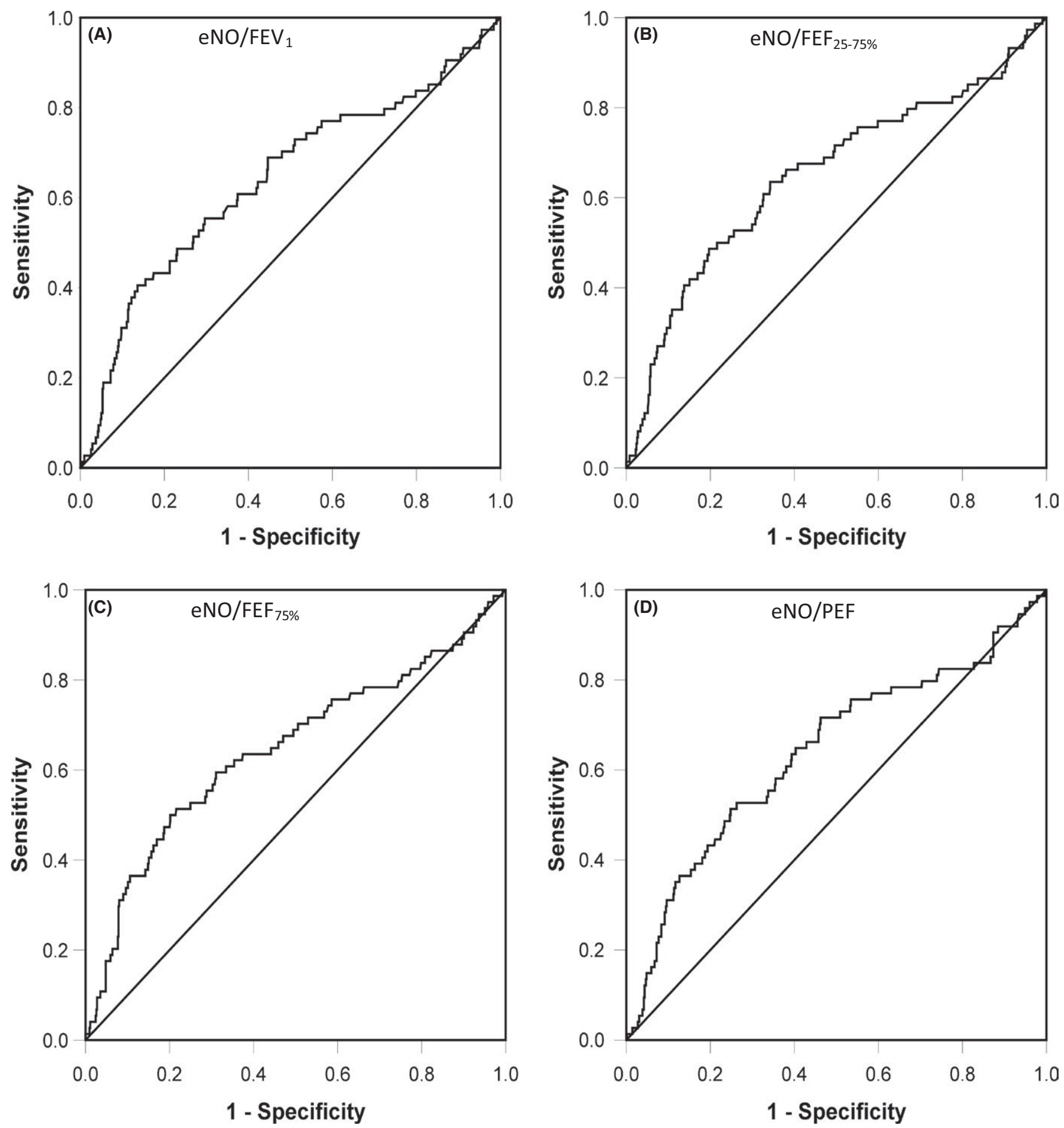

FIGURE 1 Receiver operating characteristic (ROC) curves for asthma diagnosing using: (A) exhaled NO adjusted for FEV1 (AUC = 0.640 , $P<.001$ ); (B) exhaled NO adjusted for $\mathrm{FEF}_{25 \%-75 \%}$ (AUC = 0.652, $P<.001$ ); (C) exhaled NO adjusted for FEF $75 \%$ (AUC =0.646, $P<.001$ ); (D) exhaled NO adjusted for PEF (AUC $=0.639, P<.001$ )

\section{4 | DISCUSSION}

Our findings provide support to the preferential use of spirometryadjusted fraction of exhaled NO when asthma is suspected and for reporting control, by showing its increased performance in epidemiological studies with children. Further, we provide new indices and cut-off values that allow to distinguish between controlled and uncontrolled asthma in school aged children.

Our study has a few limitations. First, the large number of asthmatic children in our study being treated with inhaled corticosteroids, a well-known modifier of exhaled NO levels ${ }^{17,18}$ and a high prevalence of allergic rhinitis, which is usually correlated with exhaled NO levels. 

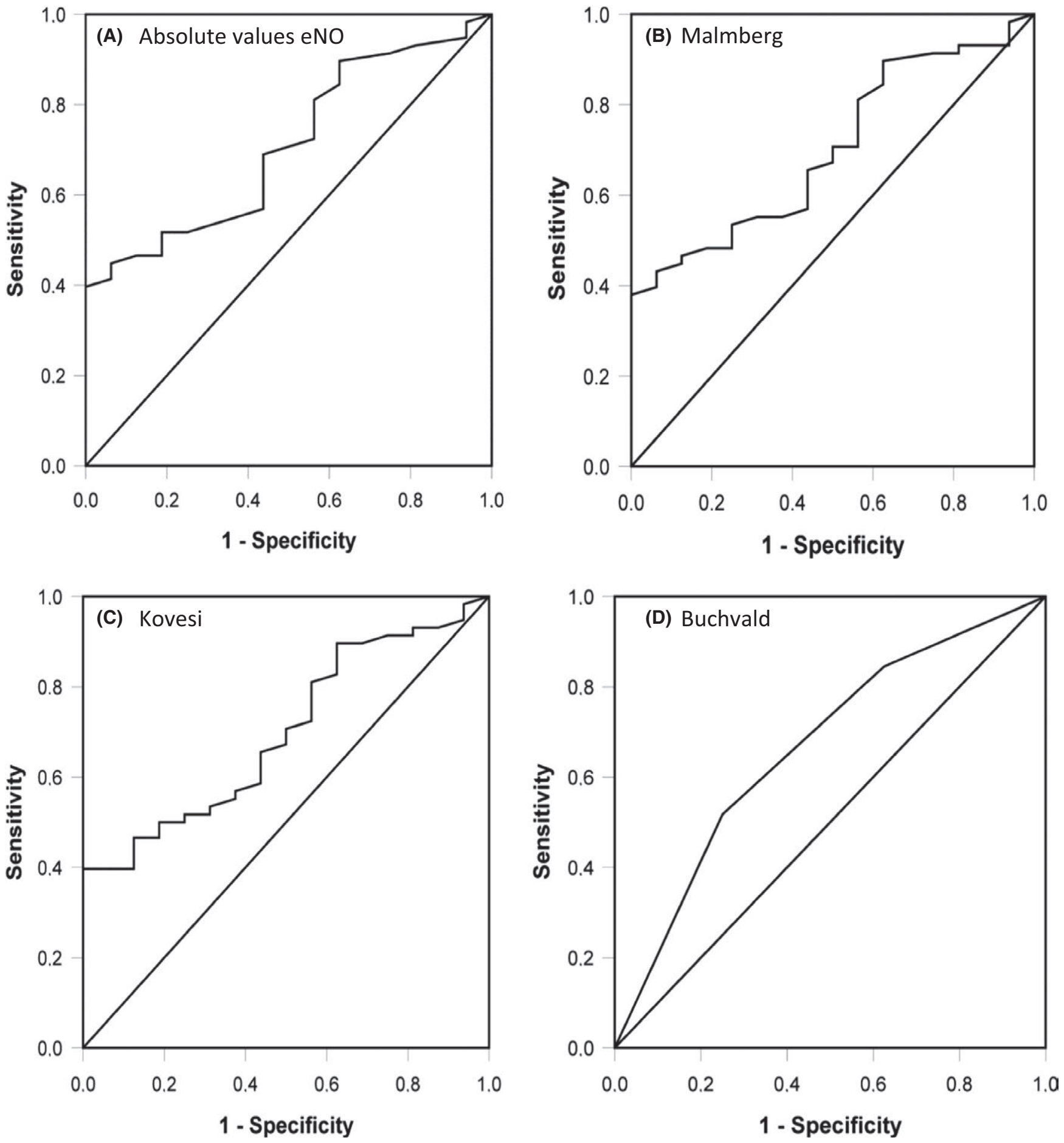

FIG URE 2 Receiver operating characteristic (ROC) curves for asthma control using: (A) absolute exhaled NO values (AUC = 0.707, $P=.011)$; (B) per cent predicted of Malmberg values (AUC = 0.701, $P=.014)$; (C) per cent predicted of Kovesi values (AUC = 0.698, $P=.016)$; (D) low, normal or high values according to Buchvald (AUC $=0.666, P=.043$ )

Secondly, our evaluations were conducted during pollen season, contributing to high exhaled NO levels, even when asthma was not present, in pollen allergic patients. ${ }^{19}$ Thirdly, the use of respiratory symptoms with high levels of exhaled NO as a definition of uncontrolled asthma, and the subsequent evaluation of an association with exhaled NO ratio may lead to a risk of circular reasoning. Nonetheless, this effect will also affect the other indices and equations in the same way. Finally, the use of airway reversibility as a marker of uncontrolled asthma. During asthma management the presence of airway reversibility does not support stepping down treatment, which would be done if disease was under control. Also, a recent study by Heffler and colleagues showed bronchodilator response to be a marker of poor controlled asthma. ${ }^{16}$ 

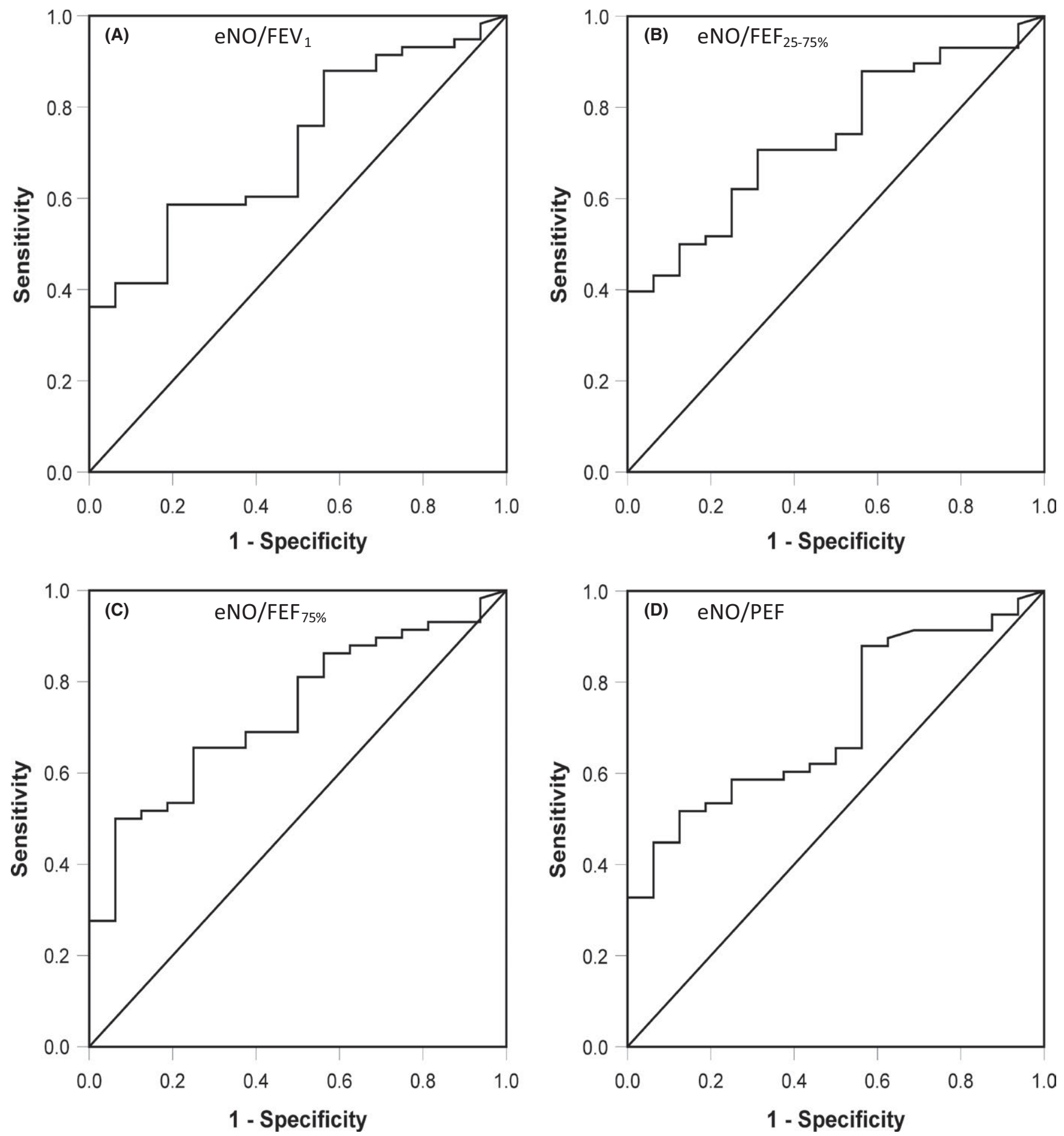

FIGURE 3 Receiver operating characteristic (ROC) curves for asthma control using: (A) exhaled NO adjusted for FEV1 (AUC = 0.712 , $P=.010$ ); (B) exhaled NO adjusted for $\mathrm{FEF}_{25 \%-75 \%}$ (AUC = 0.735, $\left.P=.004\right) ;(C)$ exhaled NO adjusted for FEF $75 \%$ (AUC =0.733, $\left.P=.004\right) ;(D)$ exhaled NO adjusted for PEF(AUC $=0.709, P=.011$ )

The ability of exhaled NO to identify asthma in children has shown conflicting results; a cut-off value of $19 \mathrm{ppb}$ has been suggested, with a sensitivity and specificity of $91 \%$ and $87 \%$, respectively, for diagnosing mild asthma. ${ }^{20}$ This was partially supported by a large real-life study of school aged children, where levels of exhaled NO above $15.8 \mathrm{ppb}$ showed to be reliable to identify asthma. ${ }^{21}$ Nonetheless, a different work suggested that exhaled NO was associated with atopy, but not asthma. ${ }^{22}$

The usefulness of spirometry-adjusted fraction of exhaled NO has been recently suggested for the diagnosis of asthma in children, adolescents and young adults by Grzelewski et al ${ }^{14}$ Cut-off points of $11.00 \mathrm{ppb} / \mathrm{L}, 12.53 \mathrm{ppb} / \mathrm{L}$ and $11.81 \mathrm{ppb} / \mathrm{L}$ for the ratios 


\begin{tabular}{|lclc|} 
& Cut-off value & Sensitivity (\%) & $\begin{array}{l}\text { Specificity } \\
\text { (\%) }\end{array}$ \\
\hline Exhaled NO/FEV1 & $9.72 \mathrm{ppb} / \mathrm{L}$ & 59 & 81 \\
\hline Exhaled NO/FEF25\%-75\% & $15.7 \mathrm{ppb} / \mathrm{L} / \mathrm{s}$ & 40 & 100 \\
\hline Exhaled NO/FEF75\% & $22.1 \mathrm{ppb} / \mathrm{L} / \mathrm{s}$ & 50 & 94 \\
\hline Exhaled NO/PEF & $5.7 \mathrm{ppb} / \mathrm{L} / \mathrm{s}$ & 52 & 88 \\
\hline
\end{tabular}

TABLE 2 Cut-off values and respective specificity and sensitivity values to identify uncontrolled asthma among children with asthma between exhaled $\mathrm{NO}$ and $\mathrm{FVC}, \mathrm{FEV}_{1}, \mathrm{FEF}_{25 \%-75 \%}$, respectively were suggested by the authors for asthma diagnose. ${ }^{14}$ Our results differed, as we were not able to apply these indices. This is probably related to the studied populations; in Grzelewski et al, all children were recruited from an allergy department and had respiratory symptoms; our study was a population-based sample that represented school-age children. Therefore, our asthma prevalence was $11.2 \%$, similar to the prevalence of Portuguese population, which was much lower than the prevalence of $59.7 \%$ found in Grzelewski study. ${ }^{14}$

To our knowledge, no studies have yet evaluated the ability of spirometry-adjusted fraction of exhaled NO in assessing asthma control. Some studies have reported significant differences in exhaled NO levels between controlled and uncontrolled asthmatic children ${ }^{23}$ and showed that children with levels below 20 ppb had significantly higher scores in Asthma Control Test (ACT) and childACT (C-ACT). ${ }^{24}$ Additionally, exhaled NO levels correlated with poor asthma control status in inhaled corticosteroids (ICS) untreated cases. ${ }^{25}$ Exhaled NO also proved to be a useful tool that distinguishes asthma severity and asthma control in children when FEV fails to do it ${ }^{26}$ as well as when its defined by a clinical evaluation. ${ }^{27}$ Nevertheless, there is also evidence against the use of exhaled NO in the assessment of asthma control in children: it does not have enough discriminatory value in children under ICS treatment ${ }^{10}$ and disagrees among common measures of asthma control such as the C-ACT. ${ }^{28,29}$

Spirometry-adjusted fraction of exhaled NO had a fair accuracy to distinguish between controlled and uncontrolled asthma. We found that $78 \%$ of the children had uncontrolled disease, defined by an increase of at least $12 \%$ of the $\mathrm{FEV}_{1}$ after salbutamol or respiratory symptoms with exhaled NO level above than $35 \mathrm{ppb}$. This figure is fairly similar to other studies that reported about $75 \%$ uncontrolled asthma between 5 and 18 years of age. ${ }^{10,23,30,31}$

In our study, the ratio of exhaled $\mathrm{NO} / \mathrm{FEF}_{25 \%-75 \%}$ arises as the best to assess asthma control, while the exhaled $\mathrm{NO}$ adjusted for $\mathrm{FEV}_{1}$ as the most sensitive. The higher sensitivity of exhaled NO/FEV ${ }_{1}$ can be explained by the use of $\mathrm{FEV}_{1}$ as a gold standard when assessing lung function as the main determinant of bronchodilation or bronchial challenge tests, as well as in the classification of severity in spirometric abnormalities and prognostic outcomes in pulmonary obstructive diseases. Relatively to exhaled NO/FEF $25 \%-75 \%$, Siroux et $\mathrm{al}^{32}$ found that small airway obstruction, as assessed based on $\mathrm{FEF}_{25 \%-75 \%}$, might contribute to the long-term persistence of asthma and the subsequent risk for poor asthma outcomes, independently from effects of the large airways. Our findings may reflect the physiologic dysfunction in the clinical expression of asthma control; however, it is not possible to assert whether small airways inflammation also contribute to this clinical outcome, as a study with a different methodology, with alveolar and exhaled NO in relation to small airways function parameters would be a better approach.

A moderate-to-strong agreement between spirometry-adjusted fraction of exhaled NO cut-off levels and those from the ATS ${ }^{3}$ was observed: while exhaled $\mathrm{NO} / \mathrm{FEF}_{25 \%-75 \%}$ identified further $7 \%$ (5 of 74) of children with uncontrolled asthma that would be missed by the ATS cut-off level, the later identified $3 \%$ ( 2 of 74 ) of children with uncontrolled asthma that were not identified by exhaled $\mathrm{NO} / \mathrm{FEF}_{25 \%-75 \%}$. A change of $7 \%$ is an important difference when analysing large cohorts or epidemiologic studies; therefore, the use of combined measures exhaled $\mathrm{NO} / \mathrm{FEV}_{1}$ and exhaled $\mathrm{NO} / \mathrm{FEF}_{25 \%-75 \%}$ could provide a best approach identifying asthma control. Also, the agreement between these two measures is not perfect, so they identify essentially different subjects.

Determinants of exhaled NO includes age, sex, body height, atopy and smoking status, ${ }^{19,33}$ but in our study exhaled NO correlates only with age, and in spite of a significant correlation, it is weak and was not possible to derive any equation of reference values (results not shown). In developing individuals, exhaled NO increases until 14 years in females and 16 in males, and similar development is observed for anatomic dead space volume. ${ }^{34}$ This finding suggests that the growth dependency in exhaled NO levels is probably due to growth-related increase in the airway area producing NO. Therefore, the spirometry adjustment could be regarded as a way to normalize this growth effect.

The use of the combined value of spirometry parameters and exhaled NO improves the diagnostic ability and better reflects disease control than either one alone. We also found that this exhaled $\mathrm{NO} /$ spirometry parameters index performs better in the non-atopic group to identify uncontrolled asthma. This may be due to a large number of false-positive results in the atopic population, which have higher values of exhaled NO, even when they achieve asthma control, as $73 \%$ of children with controlled asthma maintained increased NO levels. ${ }^{23}$ We now can conclude that the use of spirometryadjusted fraction of exhaled NO improves asthma identification as well as asthma control assessment in school aged children and we suggest its use in epidemiological studies to assess children with asthma-like symptoms. 


\section{ACKNOWLEDGMENTS}

Authors gratefully acknowledge the participants and their families for their kindness, and participating schools and their staff for their help and support. Authors gratefully acknowledge the funding of Project NORTE-01-0145-FEDER-000010-Health, Comfort and Energy in the Built Environment (HEBE), cofinanced by Programa Operacional Regional do Norte (NORTE2020), through Fundo Europeu de Desenvolvimento Regional (FEDER) and of the Foundation for Science and Technology schoolarships SFRH/BD/108605/2015 and SFRH/ $\mathrm{BD} / 112269 / 2015$.

\section{ORCID}

Carla Martins (iD http://orcid.org/0000-0002-4643-2285

João Rufo (iD http://orcid.org/0000-0003-1175-242X

\section{REFERENCES}

1. Gomersal T, Harnan S, Essat M, et al. A systematic review of fractional exhaled nitric oxide in the routine management of childhood asthma. Pediatr Pulmonol. 2016;51:316-328.

2. ATS/ERS recommendations for standardized procedures for the online and offline measurement of exhaled lower respiratory nitric oxide and nasal nitric oxide, 2005. Am J Respir Crit Care Med 2005;171:912-930.

3. Dweik RA, Boggs PB, Erzurum SC, et al. An official ATS clinical practice guideline: interpretation of exhaled nitric oxide levels (FENO) for clinical applications. Am J Respir Crit Care Med. 2011;184:602-615.

4. van der Valk RJ, Duijts L, Timpson NJ, et al. Fraction of exhaled nitric oxide values in childhood are associated with 17q11.2-q12 and 17q12-q21 variants. J Allergy Clin Immunol. 2014;134:46-55.

5. Lehtimaki L, Csonka P, Makinen E, Isojarvi J, Hovi SL, AhovuoSaloranta A. Predictive value of exhaled nitric oxide in the management of asthma: a systematic review. Eur Respir J. 2016;48:706-714.

6. Tang S, Xie Y, Yuan C, Sun X, Cui Y. Fractional exhaled nitric oxide for the diagnosis of childhood asthma: a systematic review and metaanalysis. Clin Rev Allergy Immunol. 2016; https://link.springer.com/article/10.1007\%2Fs12016-016-8573-4 [Epub ahead of print]

7. Petsky HL, Cates CJ, Li A, Kynaston JA, Turner C, Chang AB. Tailored interventions based on exhaled nitric oxide versus clinical symptoms for asthma in children and adults. Cochrane Database Syst Rev 2009;4:CD006340.

8. de Jongste JC, Carraro S, Hop WC, Baraldi E. Daily telemonitoring of exhaled nitric oxide and symptoms in the treatment of childhood asthma. Am J Respir Crit Care Med. 2009;179:93-97.

9. Horak F, Doberer D, Eber E, et al. Diagnosis and management of asthma - Statement on the 2015 GINA Guidelines. Wien Klin Wochenschr. 2016;128:541-554.

10. Meena RK, Raj D, Lodha R, Kabra SK. Fractional exhaled nitric oxide for identification of uncontrolled asthma in children. Indian Pediatr. 2016;53:307-310

11. Moeller A, Carlsen KH, Sly PD, et al. Monitoring asthma in childhood: lung function, bronchial responsiveness and inflammation. Eur Respir Rev. 2015;24:204-215.

12. Lehtimaki L, Csonka P, Makinen E, Isojarvi J, Hovi SL, AhovuoSaloranta A. Predictive value of exhaled nitric oxide in the management of asthma: a systematic review. Eur Respir J. 2016;48: 706-714.

13. Tsilogianni Z, Ntontsi P, Papaioannou Al, Bakakos P, Loukides S. Biomarkers guided treatment strategies in adult patients with asthma: ready for the clinical field? Arch Immunol Ther Exp (Warsz). 2017:65:1-9.

14. Grzelewski T, Stelmach W, Stelmach R, et al. Spirometry-adjusted fraction of exhaled nitric oxide allows asthma diagnosis in children, adolescents, and young adults. Respir Care. 2016;61:162-172.

15. Sa-Sousa A, Jacinto T, Azevedo LF, et al. Operational definitions of asthma in recent epidemiological studies are inconsistent. Clin Transl Allergy. 2014;4:24.

16. Heffler E, Crimi C, Campisi R, et al. Bronchodilator response as a marker of poor asthma control. Respir Med. 2016;112:45-50.

17. Rajeev A, Mathai SS, Kulkarni VB. Use of exhaled nitric oxide in children with bronchial asthma. Med J Armed Forces India. 2015;71:337-339.

18. Cowan DC, Taylor DR, Peterson LE, et al. Biomarker-based asthma phenotypes of corticosteroid response. J Allergy Clin Immunol. 2015;135:877-883 e1.

19. Kim HB, Eckel SP, Kim JH, Gilliland FD. Exhaled NO: determinants and clinical application in children with allergic airway disease. Allergy Asthma Immunol Res. 2016;8:12-21.

20. Perez Tarazona S, Martinez Camacho RM, Alfonso Diego J, Escolano Serrano S, Talens Gandia J. Diagnostic value of exhaled nitric oxide measurement in mild asthma. An Pediatr (Barc). 2011;75:320-328.

21. Grzelewski T, Witkowski K, Makandjou-Ola E, et al. Diagnostic value of lung function parameters and FeNO for asthma in schoolchildren in large, real-life population. Pediatr Pulmonol. 2014;49:632-640.

22. Mikalsen IB, Halvorsen T, Oymar K. Exhaled nitric oxide is related to atopy, but not asthma in adolescents with bronchiolitis in infancy. BMC Pulm Med. 2013;13:66.

23. Staticescu S, Panta PC, Tatar S, Culea M, Nanulescu MV. The role of exhaled nitric oxide assessment in children with bronchial asthma. Clujul Med. 2013;86:357-361.

24. Soto-Ramos M, Castro-Rodriguez JA, Hinojos-Gallardo LC, Hernandez-Saldana R, Cisneros-Castolo M, Carrillo-Rodriguez V. Fractional exhaled nitric oxide has a good correlation with asthma control and lung function in latino children with asthma. J Asthma. 2013;50:590-594.

25. Visitsunthorn N, Prottasan P, Jirapongsananuruk O, Maneechotesuwan $\mathrm{K}$. Is fractional exhaled nitric oxide (FeNO) associated with asthma control in children? Asian Pac J Allergy Immunol. 2014;32:218-225.

26. Delgado-Corcoran C, Kissoon N, Murphy SP, Duckworth LJ. Exhaled nitric oxide reflects asthma severity and asthma control. Pediatr Crit Care Med. 2004;5:48-52.

27. Meyts I, Proesmans M, De Boeck K. Exhaled nitric oxide corresponds with office evaluation of asthma control. Pediatr Pulmonol. 2003;36:283-289.

28. Green RJ, Klein M, Becker $\mathrm{P}$, et al. Disagreement among common measures of asthma control in children. Chest. 2013;143:117-122.

29. Ito Y, Adachi Y, Itazawa T, et al. Association between the results of the childhood asthma control test and objective parameters in asthmatic children. J Asthma. 2011;48:1076-1080.

30. Montalbano L, Cilluffo G, Gentile M, et al. Development of a nomogram to estimate the quality of life in asthmatic children using the Childhood Asthma Control Test. Pediatr Allergy Immunol. 2016;27:514-520.

31. Attanasi M, Consilvio NP, Rapino D, et al. Bronchial hyperresponsiveness to mannitol, airway inflammation and Asthma Control Test in atopic asthmatic children. Arch Med Sci. 2016;12:137-144.

32. Siroux $\mathrm{V}$, Boudier $\mathrm{A}$, Dolgopoloff $\mathrm{M}$, et al. Forced midexpiratory flow between $25 \%$ and $75 \%$ of forced vital capacity is associated with long-term persistence of asthma and poor asthma outcomes. J Allergy Clin Immunol. 2016;137:1709-1716 e6.

33. Al-Shamkhi N, Alving K, Dahlen SE, et al. Important non-diseaserelated determinants of exhaled nitric oxide levels in mild asthma - results from the Swedish GA(2) LEN study. Clin Exp Allergy. 2016:46:1185-1193. 
34. Jacinto T, Malinovschi A, Janson C, Fonseca J, Alving K. Evolution of exhaled nitric oxide levels throughout development and aging of healthy humans. J Breath Res. 2015;9:036005.

\section{SUPPORTING INFORMATION}

Additional Supporting Information may be found online in the supporting information tab for this article.
How to cite this article: Martins C, Silva D, Severo M, et al. Spirometry-adjusted fraction of exhaled nitric oxide increases accuracy for assessment of asthma control in children. Pediatr Allergy Immunol. 2017;28:754-762. https://doi.org/10.1111/ pai.12803 